$\xi=$

\title{
Performance evaluation of Weibull function for wind data analysis in two selected locations in North-Western, Nigeria
}

\author{
Boluwaji Moses Olomiyesan * \\ Examination Development Department, National Examinations Council (NECO), P.M.B. 159, Minna, Niger State, Nigeria \\ *Corresponding author E-mail: olomiyebolu@yahoo.com
}

\begin{abstract}
In this study, the predictive ability of two-parameter Weibull distribution function in analyzing wind speed data was assessed in two selected sites with different mean wind speeds in the North-Western region of Nigeria. Twenty-two years wind speed data spanning from 1984 to 2005 was used in the analysis. The data were obtained from the Nigerian Meteorological Agency (NIMET) in Lagos. The results of the analysis show that Weibull function is suitable for analyzing measured wind speed data and in predicting the wind-power density in both locations and that Weibull function is not discriminative between locations with high and low mean wind speeds in analyzing wind data. The annual mean wind speeds for the two sites (Sokoto and Yelwa) are $7.99 \mathrm{~ms}^{-1}$ and $2.59 \mathrm{~ms}^{-1}$ respectively, while the annual values of the most probable wind speed and the maximum, energy-carrying wind speeds are respectively:3.52 and $4.34 \mathrm{~ms}^{-1}$ for Yelwa and 8.33 and $9.02 \mathrm{~ms}^{-1}$ for Sokoto. The estimated annual wind power densities for Yelwa and Sokoto are respectively 36.91 and 359.96 $\mathrm{Wm}^{-2}$. Therefore, Sokoto has a better prospect for wind power generation.
\end{abstract}

Keywords:Weibull Distribution Function; Wind Speed; Wind Power Density; Nigeria.

\section{Introduction}

Wind as a renewable energy source is inexhaustible and environmentally friendly. It is considered as a promising and one of the most valuable renewable energy sources needed for meeting the increasing energy need of the world population [1].Also, wind energy is said to be the most common and fastest growing renewable energy technology in terms of percentage of annual growth of installed capacity [2]. The growing interest in wind energy utilization has resulted in increased number of studies on wind energy resources assessment, especially in developing nations where reliable and accurate wind resource data is not readily available. Effective utilization of wind energy either for power generation or other mechanical applications requires careful investigation of wind resources due to its fluctuation with height, terrain as well as, its daily, seasonal and annual variation [3].

Analysis of wind speed data has been carried out by a good number of researchers using various statistical and mathematical models [1], [4], [5], [6]. These models include: Rayleigh, Weibull, Logistic, Normal, Gamma, Beta, Gaussian and Lognormal distributions [7], [8], [9]. Among the available statistical models, Weibull and Rayleigh functions are the widely accepted and most commonly used models for wind data analysis [10]; but Weibull distribution is acclaimed to give the best fit for describing wind speed variations at a given location [11], [12], [13]. Joseph and Hennesessey [14] however, reported that for locations with very low average wind speeds, the Weibull distribution does not fit well the location's wind speed distribution. The current research therefore aims at investigating the predictive ability of Weilbull function by using it to evaluate the wind speed distribution in two sites with different mean wind speeds in North-Western region of
Nigeria. The two selected locations are Sokoto (Latitude- $13.05^{\circ} \mathrm{N}$, Longitude- $5.15^{\circ} \mathrm{E}$, Altitude- $285 \mathrm{~m}$ ) and Yelwa (Latitude- 11.80 , Longitude- $4.34^{\circ} \mathrm{E}$, Altitude- $252 \mathrm{~m}$ ). Wind speed is high at Sokoto, while it is low at Yelwa. This makes the two sites suitable for a comparative study to verify the predictive ability of Weibull function in locations with different mean wind speed.

\section{Materials and method}

\subsection{Data collection}

Wind speed measured at 10 metres above the sea level was used in this study. The dataset span a period of twenty-two years (1984 2005) and was collected from the Nigerian Meteorological Agency (NIMET), Oshodi, Lagos.

\subsection{Statistical analysis of wind data}

The analysis of wind distribution in the selected sites was carryout using Weibull distribution function. Weibull probability density function, $\mathrm{f}_{\mathrm{w}}(\mathrm{v})$, and the corresponding cumulative probability function, $F_{w}(v)$, can be expressed as [15]:

$$
\begin{aligned}
& f_{w}(v)=\left(\frac{k}{c}\right)\left(\frac{v}{c}\right)^{k-1} \exp \left[-\left(\frac{v}{c}\right)^{k}\right] \\
& F_{w}(v)=1-\exp \left[-\left(\frac{v}{c}\right)^{k}\right]
\end{aligned}
$$

Where:

$$
\mathrm{v}=\text { wind speed }\left(\mathrm{ms}^{-1}\right)
$$


$\mathrm{c}=$ scale factor $\left(\mathrm{ms}^{-1}\right)$

$\mathrm{k}=$ shape factor (dimensionless)

Kidmo et al. [5] describe six numerical methods for determining the values of the Weibull parameters $\mathrm{k}$ and $\mathrm{c}$ from measured wind data. These methods include:Graphical Method (GM), Energy Pattern Factor Method (EPFM), Moment Method (MM), Maximum Likelihood Method (MLM), Modified Maximum Likelihood Method (MMLM) and Empirical Method (EM) or Standard Deviation Method (STM). The values of Weibull parameters $\mathrm{k}$ and $\mathrm{c}$ were calculated using standard deviation method. This method has relatively simple expressions when compared with other methods and is useful where only the mean wind speed and standard deviation are available [1], [16], [17].The standard deviation method is expressed in equations (3) and (4) as given by [16]:

$$
\begin{aligned}
& \mathrm{k}=\left(\frac{\sigma}{\mathrm{v}_{\mathrm{m}}}\right)^{-1.086} \\
& \mathrm{c}=\frac{\mathrm{V}_{\mathrm{m}}}{\Gamma\left(1+\frac{1}{\mathrm{k}}\right)}
\end{aligned}
$$

Alternatively, c can be determined from the expression given by [14]:

$\mathrm{c}=\mathrm{v}_{\mathrm{m}}\left(\frac{\mathrm{k}^{2.6674}}{0.184+\left(0.816 \mathrm{k}^{2.73859}\right)}\right)$

$\sigma=\left[\frac{1}{N-1} \sum_{i=1}^{N}\left(v_{i}-v_{m}\right)^{2}\right]^{1 / 2}$

Where:

$\sigma=$ standard deviation

$\mathrm{V}_{\mathrm{m}}=$ mean wind speed $\left(\mathrm{ms}^{-1}\right)$

$\mathrm{V}_{\mathrm{i}}=$ observed wind speed $\left(\mathrm{ms}^{-1}\right)$

$\mathrm{N}=$ number of months in the period of time considered and

$\Gamma(\mathrm{x})$ is the gamma function, which is defined as:

$$
\Gamma(\mathrm{x})=\int_{0}^{\infty} \mathrm{t}^{\mathrm{x}-1} \mathrm{e}^{-\mathrm{t}} \mathrm{dt}
$$

Other useful parameters for wind resources analysis that can be expressed in terms of Weibull shape and scale factors, $\mathrm{k}$ and $\mathrm{c}$, are the maximum energy carrying-wind speed and the most probable wind speed. The maximum energy carrying-wind speed, vEmax and the most frequent wind speed, $v_{m p}$ can be expressed as shown by equations (7) and (8) respectively [18]:

$\mathrm{V}_{\mathrm{E} \max }=\mathrm{c}\left(\frac{\mathrm{k}+2}{\mathrm{k}}\right)^{\frac{1}{\mathrm{k}}}$

$\mathrm{V}_{\mathrm{mp}}=\mathrm{c}\left(\frac{\mathrm{k}-1}{\mathrm{k}}\right)^{\frac{1}{\mathrm{k}}}$

Similarly, the wind power density, $\mathrm{P}(\mathrm{v})$, can be expressed either in term of the wind speed or in terms of the Weibull shape and scale parameters, $\mathrm{k}$ and $\mathrm{c}$, using the correlation given by [19]:

$P(v)=\frac{1}{2} \rho v^{3}$

$\mathrm{P}(\mathrm{v})=\frac{1}{2} \rho c^{3} \Gamma\left(1+\frac{3}{\mathrm{k}}\right)$

Where:

$\mathrm{P}(\mathrm{v})=$ Wind Power Density $\left(\mathrm{Wm}^{-2}\right)$

$\mathrm{k}=$ Weibull shape parameter

$\mathrm{c}=$ Weilbull scale parameter

$\mathrm{v}=$ Wind speed

$\rho=$ Air density at the site, which can be expressed in the form:

$\rho=\rho o-1.194 \times 10^{-4} \times \mathrm{H}_{\mathrm{m}}$

Where $\mathrm{H}_{\mathrm{m}}$ is the site elevation in meters and $\rho 0$ is the air density value at sea level usually taken as $1.225 \mathrm{kgm}^{-3}$.

\section{Results and discussion}

The graphic representation of the monthly mean wind speed recorded for the entire study period of 22 years for the two selected sites are presented in Figures 1 and 2.

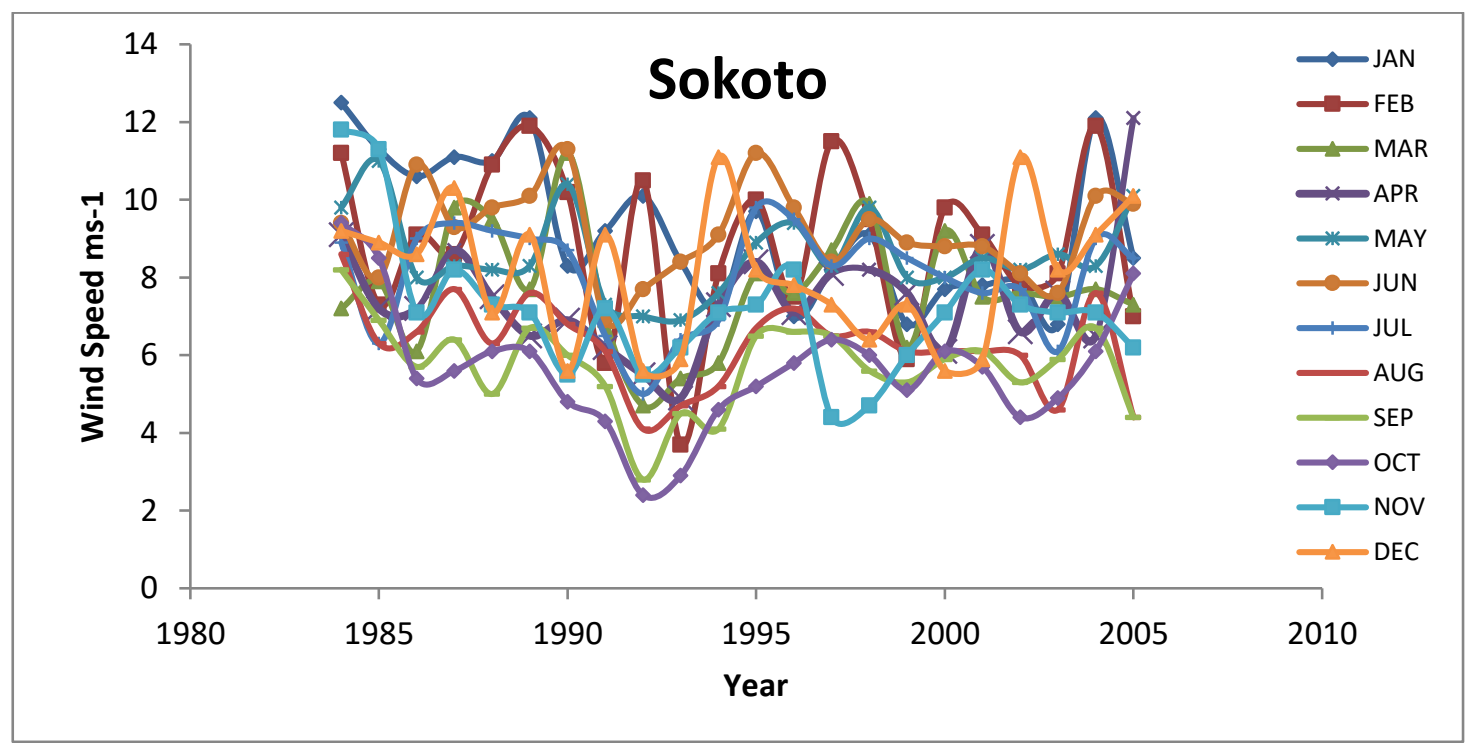

Fig. 1: Monthly Mean Wind Speeds for Sokoto (1984-2005). 


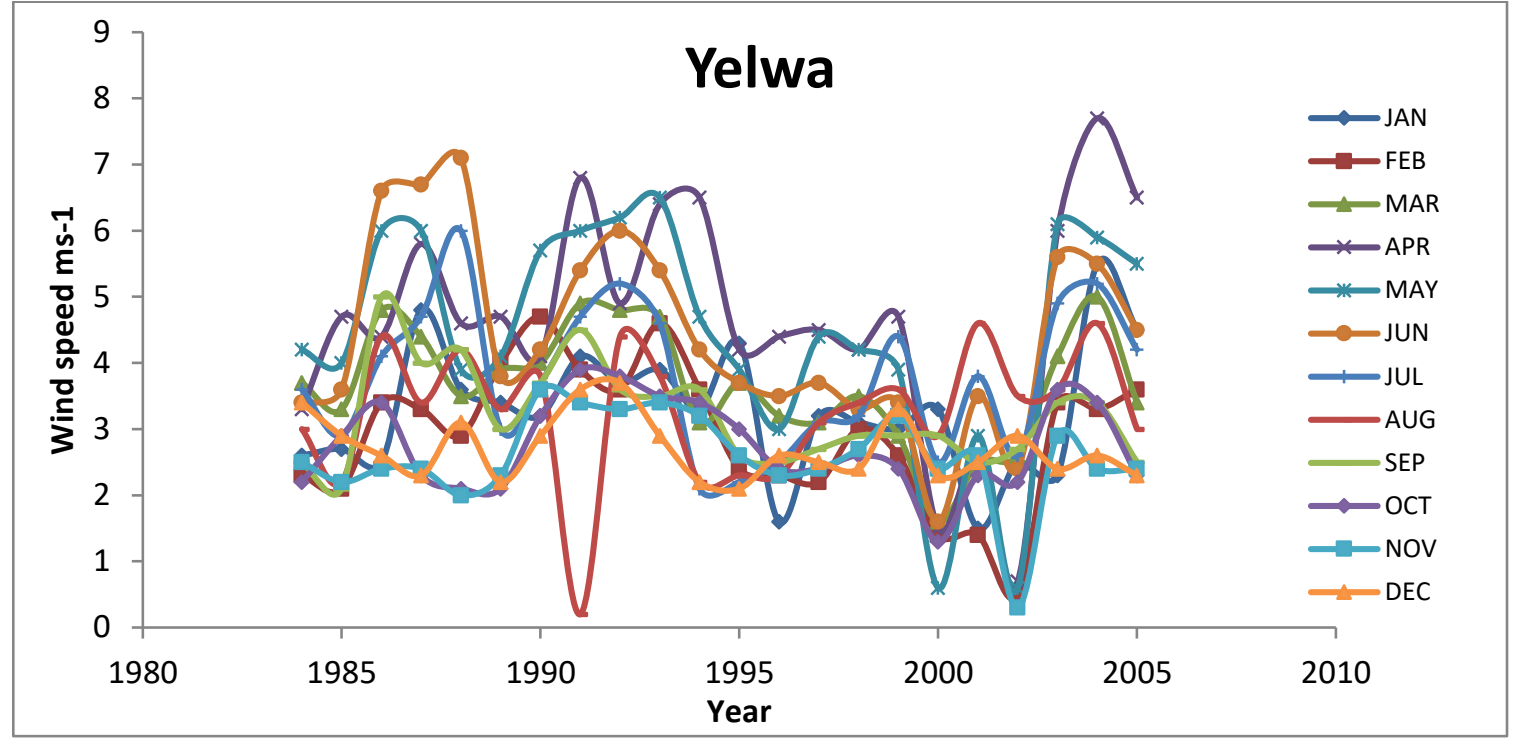

Fig. 2: Monthly Mean Wind Speeds for Yelwa (1984-2005).

Figures 1 and 2 reveal that wind speeds fluctuate from year to year. During the period under study, the highest monthly mean wind speed recorded were $12.5 \mathrm{~ms}^{-1}$ in January, 1984 for Sokoto and $7.7 \mathrm{~ms}^{-1}$ in April, 2004 for Yelwa, while the lowest monthly mean wind speed are $2.4 \mathrm{~ms}^{-1}$ in October, 1992 for sokoto and 0.2 $\mathrm{ms}^{-1}$ in August, 1991 for Yelwa. The annual mean wind speeds recorded for the period of the study are: $7.99 \mathrm{~ms}^{-1}$ for Sokoto and $2.59 \mathrm{~ms}^{-1}$ for Yelwa.

\subsection{Wind speed frequency distribution}

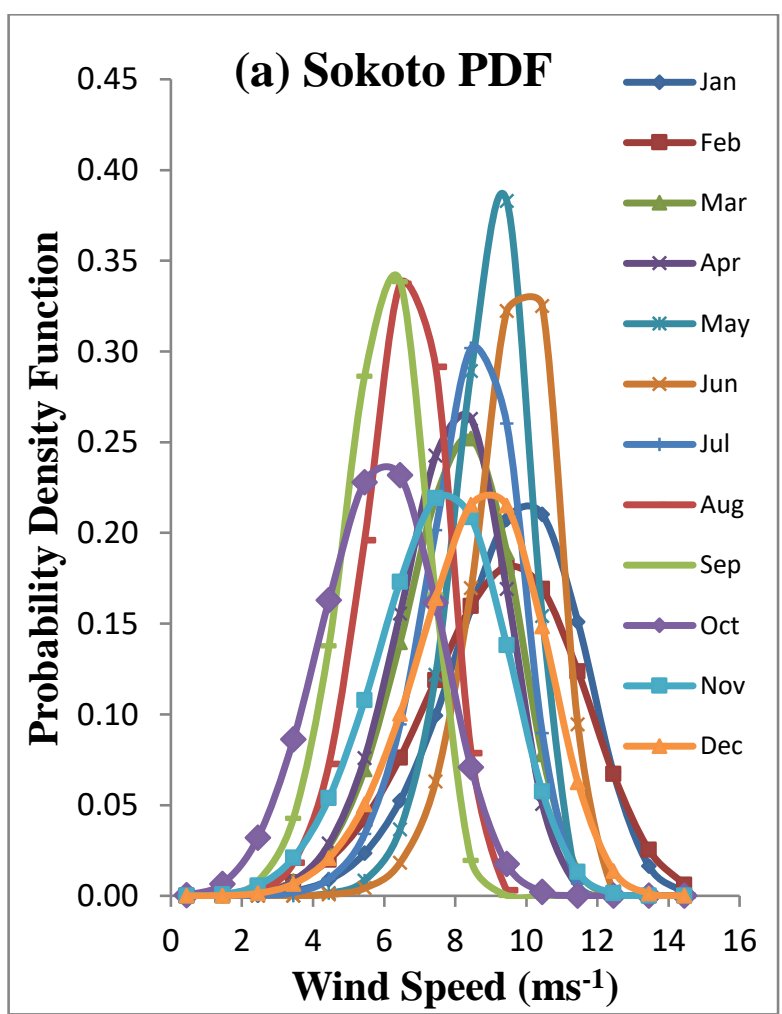

The monthly probability density and cumulative distribution derived from the time series data for the whole period for Sokoto and Yelwa are shown in Figures 3 - 4 (a \& b) respectively. The PDF and CDF plots show that all the curves of the monthly wind profiles follow the similar distribution pattern. The variation in shapes of PDF and CDF plots are due to the varying values of the Weilbull parameters $\mathrm{c}$ and $\mathrm{k}$. The parameter, c, determines the spread of the distribution, while the shape parameter, $\mathrm{k}$, indicates the peak of the wind distribution.

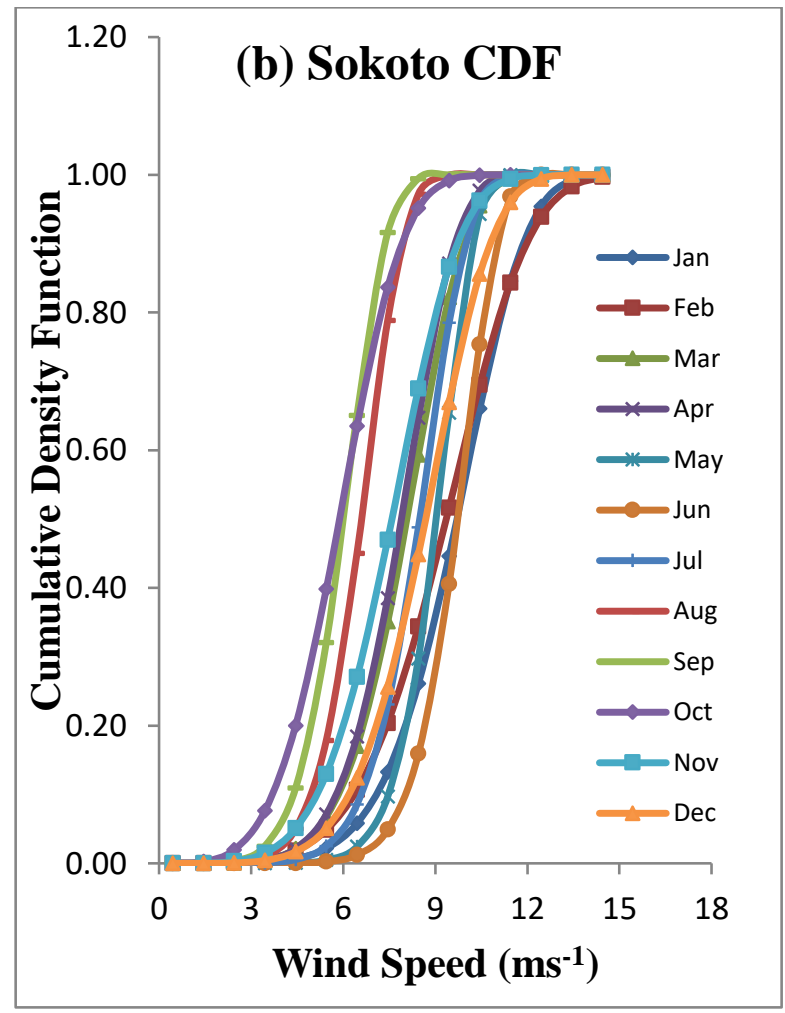

Fig. 3: Monthly Wind Distribution for Sokoto (A) PDF and (B) CDF 

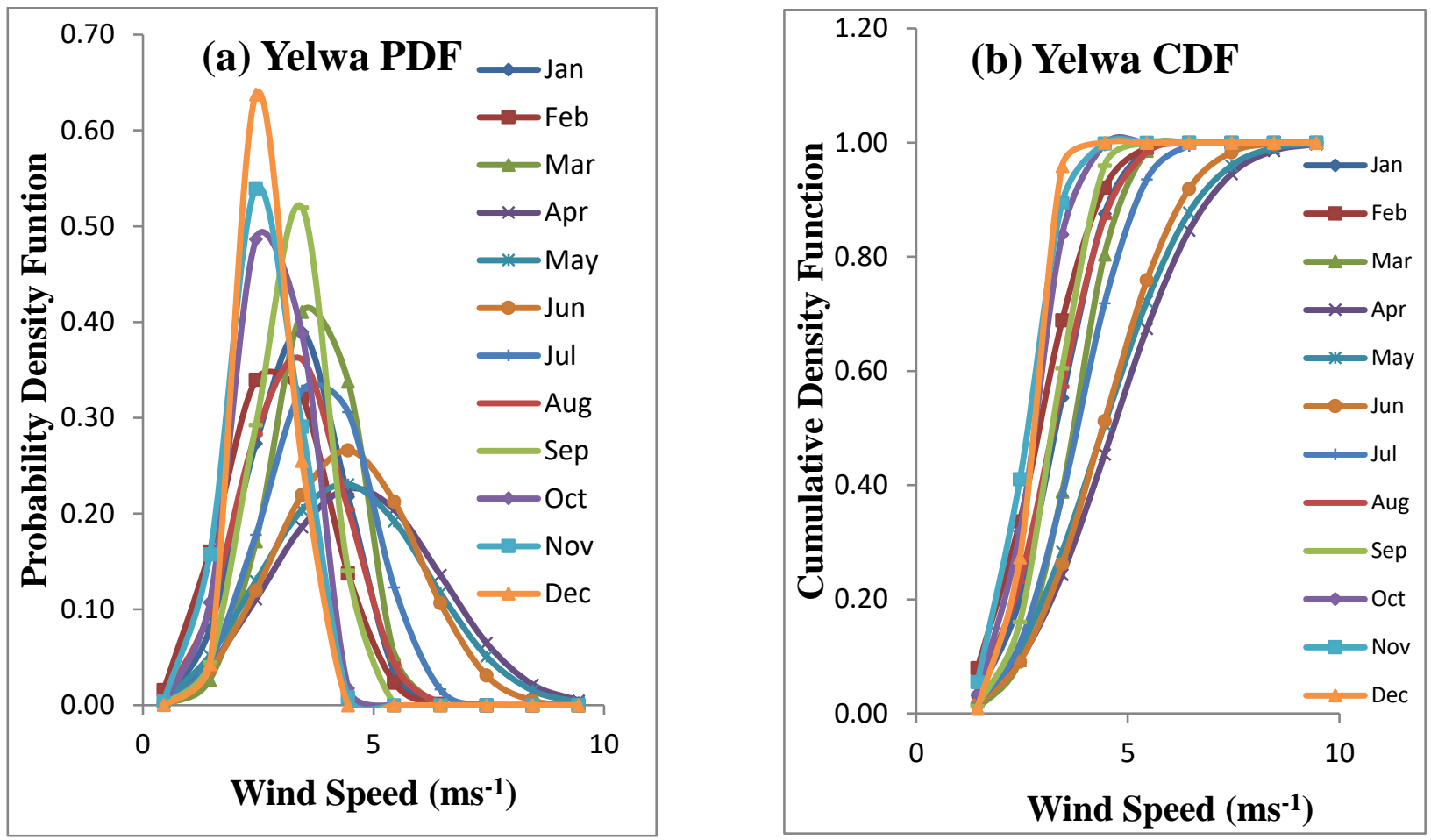

Fig. 4: Monthly Wind Distribution for Yelwa (A) PDF and (B) CDF.
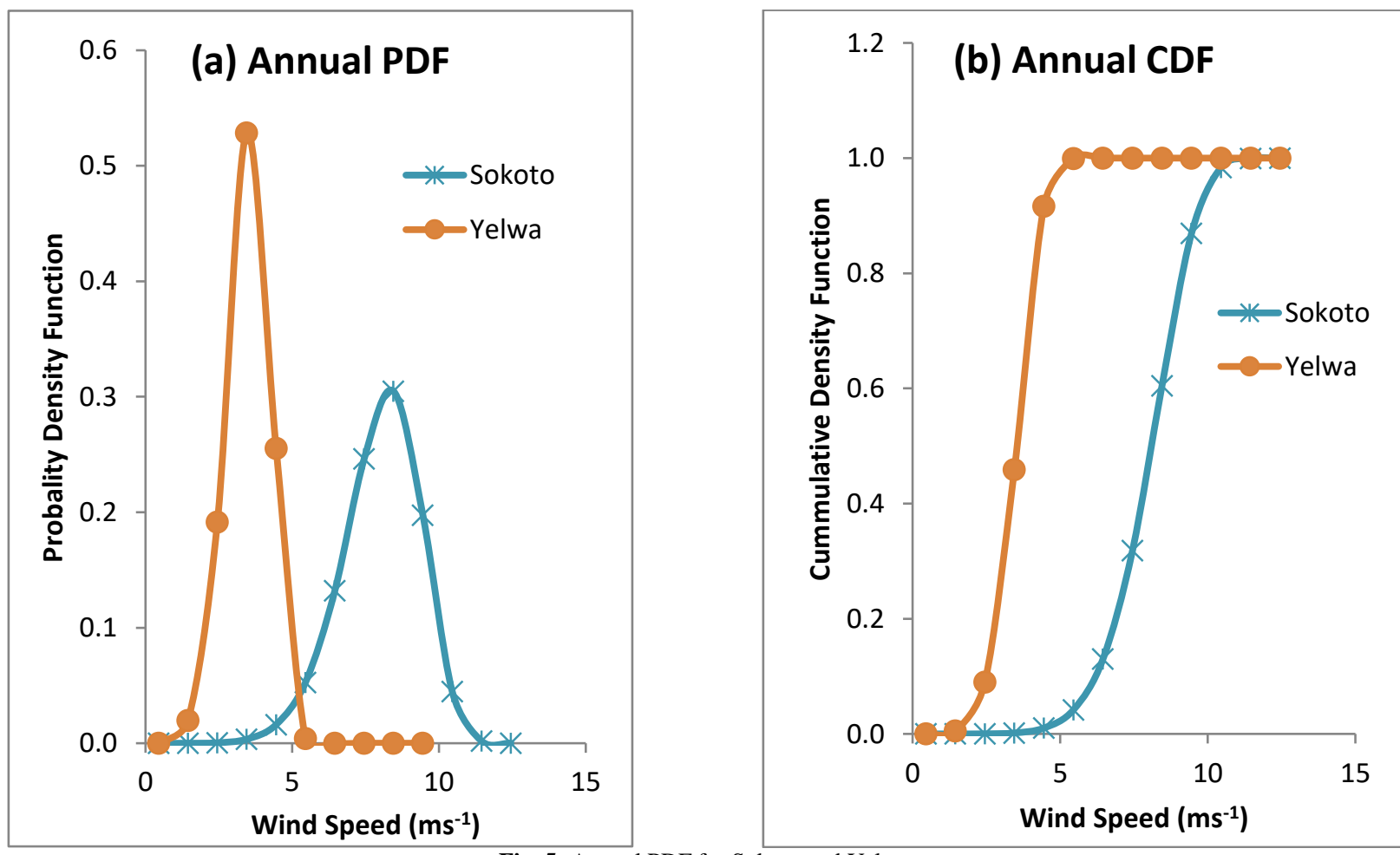

Fig. 5: Annual PDF for Sokoto and Yelwa.

The plot of the probability density function (PDF) illustrates the fraction of time for which a given wind speed possibly prevails at a location [1]. The peak of the PDF curve indicates the most frequent velocity, whereas the plot of the cumulative distribution function is used for estimating the time for which wind speed is within a certain speed interval [1].The plots of the monthly PDF shown in Figures 3(a) and 4 (a) demonstrate that the wind profiles for these locations and months follow the same distribution pattern. It can further be noted that the PDF plot for sokoto shows a wider data spread than that of Yelwa.

Similarly, the CDF plots in Figures 3(b) and 4 (b) show that: at Sokoto, $40 \%$ of the data are in the wind speed range of $5.5-9.5$ $\mathrm{ms}^{-1}$ and below, while $80 \%$ of the data are within wind speed interval of $7-11.2 \mathrm{~ms}^{-1}$ and below; at Yelwa, $40 \%$ of the data are in the wind speed interval of $2.4-4.2 \mathrm{~ms}^{-1}$ and below, while $80 \%$ of the data are within wind speed range of $3.2-6.2 \mathrm{~ms}^{-1}$ and below. The annual probability and cumulative density functions obtained using the Weibull distribution function for Sokoto and Yelwa are shown in Figures 5(a) and (b).

From Figure 5 (a), it can be noted that the annual mean most frequent wind speeds for Sokoto and Kaduna respectively are about 8.45 and $5.45 \mathrm{~ms}^{-1}$. The cut-in wind speed which contributes to the generation of electricity from wind in most new wind turbine designs is about $3.0 \mathrm{~ms}^{-1}$ and above [20]. However, if wind turbines with cut-in wind speed of $4 \mathrm{~ms}^{-1}$ and $6 \mathrm{~ms}^{-1}$ are selected for use in the sites, it can be observed from the CDF curves in Figure 5 (b) that, the CDF values for Sokoto at wind speed of $4 \mathrm{~ms}^{-1}$ and $6 \mathrm{~ms}^{-1}$ are 0.01 and 0.08 respectively. This implies that the percentage of 
the annual wind energy above the 4.0 and $6.0 \mathrm{~ms}^{-1}$ cut-in wind speed which can contribute to the generation of electricity are respectively $99 \%$ and $92 \%$ for Sokoto and $30 \%$ and $0 \%$ for Yelwa. This also indicates that if a wind turbine with a design cut-in wind speed of $4.0 \mathrm{~ms}^{-1}$ is installed for electricity generation in these sites, the turbine will work for about $99 \%$ of the time in Sokoto and only for about $30 \%$ in Yelwa. Thus, Yelwa is not viable for wind power generation. This is in agreement with the findings of previous works [21].

\subsection{Wind power density}

The result of analysis of monthly and annual variations between the annual mean wind power densities calculated from the measured wind data and those obtained by using Weibull parameters for the two sites is shown in Figure 6.

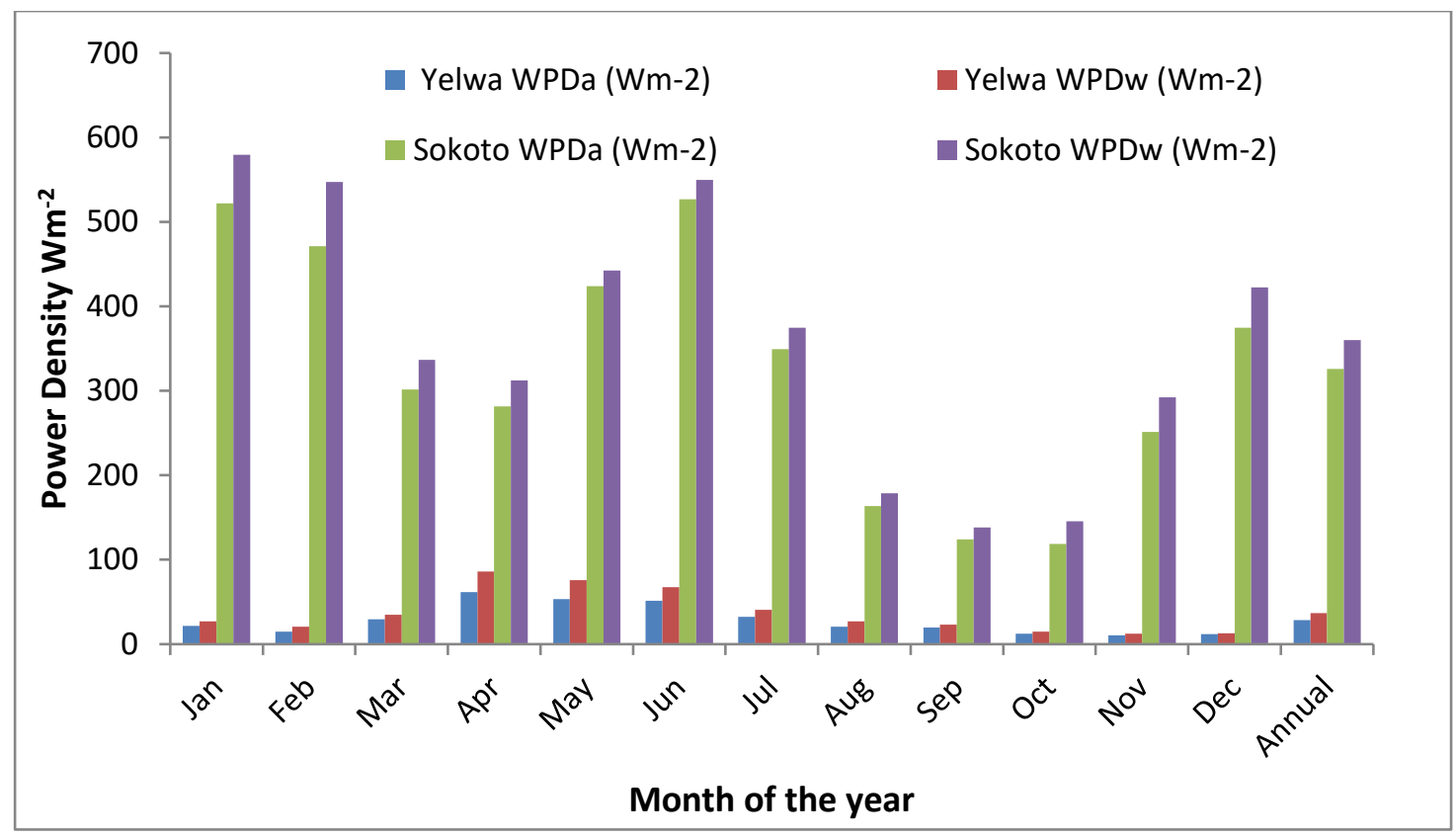

Fig. 6: Plot Showing Variations between the Power Density Distributions for Measured and Weibull Values for Sokoto and Yelwa. NOTE: WPDa is the actual Wind Power Density; WPDw is the Weilbull Wind Power Density

The variations between the actual and Weibull power densities for the two locations presented in Figure 6 indicates that the estimated Weilbull wind power density are slightly higher than the actual power density for every month of the year and on annual basis. However, the variation is less pronounced in Yelwa since the two values still fall within the same wind class in all the months of the year. On annual basis, the values of the power density are within the same wind power classification. This supports the assertion that, "Weilbull probability distribution is suitable for analysing and interpreting data of measured wind speed' [22] and is not discriminative between locations with high and low mean wind speeds. For Sokoto, the monthly Weibull WPD is in the range of $138.07-579.48 \mathrm{Wm}^{-2}$, which falls into the Wind Classes of 2 and 7 , while the monthly Weibull WPD for Yelwa is in the range of $12.55-85.85 \mathrm{Wm}^{-2}$, which falls into the Wind Class 1 of the PNL wind classification. The estimated annual wind power densities for Yelwa and Sokoto are respectively 36.91 and $359.96 \mathrm{Wm}^{-2}$. Thus, Sokoto has a better prospect than Yelwa for wind power generation.

\subsection{Wind speed characteristics}

The wind speed characteristics of a site can be described in terms of the mean wind speed $\left(\mathrm{v}_{\mathrm{m}}\right)$, most probable wind $\left(\mathrm{v}_{\mathrm{mp}}\right)$ and maximum energy-carrying wind $\left(\mathrm{v}_{\max }\right)$. The monthly and annual values of the wind speed characteristics for the two study sites at a height of $10 \mathrm{~m}$ AGL is presented in Figure 7.

Figure 7 shows that the monthly mean wind speeds curve, $\mathrm{V}$ is slightly higher than the most probable $V_{m p}$ wind speed curve for Sokoto, but for Yelwa, the monthly mean wind speed curve almost corresponds with the most probable wind speed curve. The maximum energy-carrying wing speed curve is higher than the mean wind speeds in the two locations. For Sokoto, the monthly values of $\mathrm{v}_{\mathrm{mp}}$ and $\mathrm{v}_{\max }$ are respectively in the range $6.00 \leq \mathrm{v}_{\mathrm{mp}} \leq$ $10.01 \mathrm{~ms}^{-1}$ and $6.72 \leq \mathrm{V}_{\max } \leq 10.83 \mathrm{~ms}^{-1}$. The monthly values of $\mathrm{Vmp}$ and $\mathrm{v}_{\max }$ for Yelwa are respectively in the range $2.69 \leq \mathrm{vmp} \leq 4.61$ $\mathrm{ms}^{-1}$ and $3.02 \leq \mathrm{v}_{\max } \leq 5.98 \mathrm{~ms}^{-1}$. Therefore, Sokoto has a better prospect for harvesting wind energy as indicated by the wind speed characteristics. The result further shows that strong and sufficient winds for power generation occur throughout the year in Sokoto. 


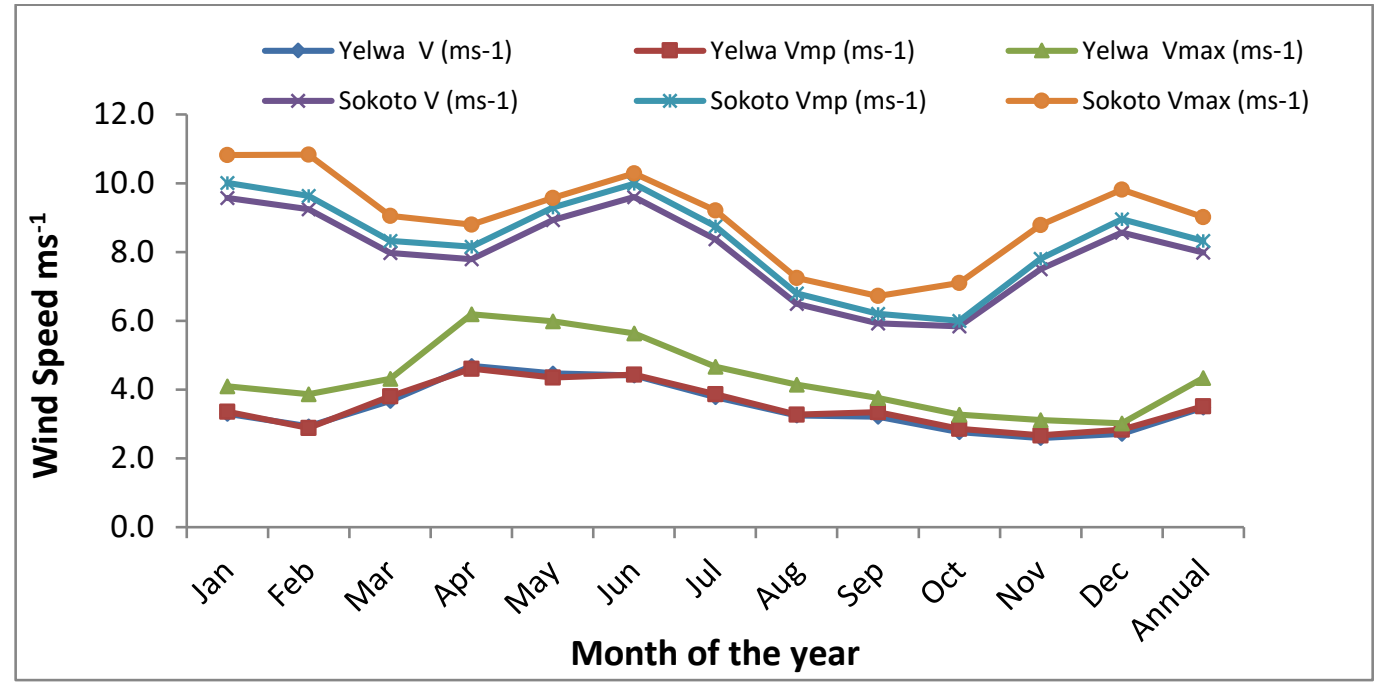

Fig. 7: Plot Comparing the Mean, Most Probable and Maximum Energy-Carrying Wind Speed for Sokoto and Yelwa.

\section{Conclusion}

In this study, the predictive ability of Weibull distribution function in analyzing wind speed data was assessed in two selected sites with different mean wind speeds in the North-Western region of Nigeria. The results of the analysis show that the Weibull function is suitable for analyzing measured wind speed data and for predicting the wind-power density in both locations. Hence, it is not discriminative between locations with high and low mean wind speeds. Other relevant findings of this study can be summarised as follows:

i) The annual mean wind speeds recorded during the period of the study are: $7.99 \mathrm{~ms}^{-1}$ for Sokoto and $2.59 \mathrm{~ms}^{-1}$ for Yelwa.

ii) The annual CDF plots for the region show that, if wind turbine with a design cut-in wind speed of $4.0 \mathrm{~ms}^{-1}$ is installed for electricity generation in the study sites, the turbine would work for more than $99 \%$ of the time in Sokoto and only about $30 \%$ of the time in Yelwa.

iii) The annual values of the most probable wind speeds and the maximum energy-carrying wind speeds are respectively: 3.52 and $4.34 \mathrm{~ms}^{-1}$ for Yelwa and 8.33 and $9.02 \mathrm{~ms}^{-1}$ for Sokoto.

iv) Based on the estimated annual values of the Weibull wind power density, the wind energy resource in Sokoto can be classified as class 6, while Yelwa is categorised as class 1 in the PNL wind classification. Therefore, Sokoto has a better prospect for harvesting wind energy for electricity generation.

\section{Acknowledgement}

The author wish to acknowledge the management and staff of Nigerian Meteorological Agency (NIMET) for providing the data used in this research.

\section{References}

[1] S. O. Oyedepo, M. S. Adaramola, S. S. Paul, Analysis of Wind Speed Data an Wind Energy Potential in Three Selected Locations in South-East Nigeria, International Journal of Energy and Environmental Engineering, 3,7(2012), https://doi.org/10.1186/22516832-3-7.

[2] H. S. Bagiorgas, G. Mihalakakou, S. Rehman, L.M. Al-Hadhrami, Wind Power Potential Assessment for Seven Buoys Data Collection Stations in Aegean Sea Using Weibull Distribution Function, Journal of Renewable and Sustainable Energy, 4,1(2012), 013119-1 013119-16.

[3] S. Rehman, Long-Term Wind Speed Analysis and Detection of its Trends Using Mann-Kendall Test and Linear Regression Method,
Arabian Journal for Science and Engineering, 38, 2(2013), 421 437. https://doi.org/10.1007/s13369-012-0445-5.

[4] O. Al-Nhoud, M. Al-Smairan, Assessment of Wind Energy Potential as a Power Generation Source in the Azraq South, Northeast Badia, Jordan. Modern Mechanical Engineering, 5 (2015), 87-96. https://doi.org/10.4236/mme.2015.53008.

[5] D. K. Kidmo, R. Danwe, S. Y. Doka, N. Djongyang, Statistical Analysis of Wind Speed Distribution Based on Six Weibull Methods for Wind Power Evaluation in Garoua, Cameroon, Revue des Energies Renouvelables, 18, 1 (2015), $105-125$.

[6] T. Hove, L. Madiye, D. Musademba, Mapping wind Power Density for Zimbabwe: A Suitable Weibull-Parameter Calculation Method, Journal of Energy in Southern Africa, 25, 4(2014), 37-47.

[7] P. Ramirez, J. A. Carta, The use of wind probability distributions derived from the maximum entropy principle in the analysis of wind energy a case study, Energy Conversion and Management,47(2005),

2564-2577 https://doi.org/10.1016/j.enconman.2005.10.027.

[8] J. A. Carta, P. Ramırez, S. Velázquez, A review of wind speed probability distributions used in wind energy analysis: case studies in the Canary Islands,Renewable Sustainable Energy Reviews, 13(2009), 933-55. https://doi.org/10.1016/j.rser.2008.05.005.

[9] A. Mostafaeipour, M. Jadidi, K. Mohammadi, A. Sedaghat, An analysis of wind energy potential and economic evaluation in Zahedan, Iran, Renewable and Sustainable Energy Reviews, 30(2014), 641-650. https://doi.org/10.1016/j.rser.2013.11.016.

[10] M. R. Ahmmad, Statistical Analysis of the Wind Resources at the Importance for Energy Production in Bangladesh, International Journal of u- and e-Service, Science and Technology, 7,2(2014), 127-136. https://doi.org/10.14257/ijunesst.

[11] M. R. Patel, Wind and Solar Power Systems(1999), CRC Press.

[12] R. Kose, M. A. Ozgur, E. A. T. Oguzhan, The analysis of wind data and wind energy potential in Kutahya, Turkey, Renewable Sustainable Energy Reviews, 8(2004), 277-88 https://doi.org/10.1016/j.rser.2003.11.003.

[13] P. Joseph, J. Hennesessey, Some aspects of wind power statistics, Journal of Applied Meteorology, 16 (1977), 119-128. https://doi.org/10.1175/15200450(1977)016<0119:SAOWPS >2.0.CO;2.

[14] S. A. Ahmed, Investigation of Wind Characteristics and Wind Energy Potential at RasGhareb Egypt, Renewable and Sustainable Energy Reviews, 15(2011), 2755.https://doi.org/10.1016/j.rser.2011.04.003.

[15] I. Dikko, D. B. Yahaya, Evaluation of Wind Power Density in Gombe, Yola and Maiduguri, North Eastern Nigeria, Journal of Research in Peace, Gender and Development, 2, 5(2012), 115-122.

[16] C. G. Justus, W. R. Hargraves, A. Mikhail, D. Grabber, Methods for Estimating Wind Speed Frequency Distributions, Journal of Applied Meteorology, 17, 3(1978)., 350 - 353. https://doi.org/10.1175/15200450(1978)017<0350:MFEWSF>2.0.CO 2

[17] F. A. L. Jowder, Wind Power Analysis and Site Matching of Wind Turbine Generators in Kingdom of Bahrain, Applied Energy, 86(2009), https://doi.org/10.1016/j.apenergy.2008.08.006

$538-545$. 
[18] O. Arslan, Technoeconomic analysis of electricity generation from wind energy in Kutahya Turkey, Energy, 35(2010), 20 131.https://doi.org/10.1016/j.energy.2009.09.002.

[19] J. N. Kamau, R. Kinyua, J. K. Gathua, Six Years of Wind Data for Marsabit, Kenya Average Over 14 m/s at 100 m Hub Height; An Analysis of the Wind Energy Potential. Renewable Energy, 35, 6(2010), 1298-1302. https://doi.org/10.1016/j.renene.2009.10.008.

[20] N. Nze-Esiaga, E. C. Okogbue, Assessment of Wind Energy Potential as a Power Generation Source in Five Locations of South Western Nigeria, Journal of Power and Energy Engineering, 2(2014), 113. https://doi.org/10.4236/jpee.2014.25001.

[21] M. A. Sodunke, K. J. Oseni, O. A.Abatan, M. A. Ajayi, A. A. Alabi, The Study of the Wind Energy Potential in the Northern Region of Nigeria, Journal of Engineering and Applied Sciences, 3(2011), 29- 42

[22] R. O. Fagbenle, J. Katende, O. O. Ajayi, J. O. Okeniyi, Assessment of Wind Energy Potential of Two Sites in North-East, Nigeria. Renewable Energy, 36(2011), 12771283.https://doi.org/10.1016/j.renene.2010.10.003. 